\title{
Are perceptions of community safety associated with respiratory illness among a low-income, minority adult population?
}

\author{
Kristen N. Arthur ${ }^{1 *}$ D, Rhonda Spencer-Hwang ${ }^{1}$, Synnøve F. Knutsen², David Shavlik', Samuel Soret ${ }^{1}$ \\ and Susanne Montgomery ${ }^{3}$
}

\begin{abstract}
Background: Growing evidence suggests social disadvantage magnifies the harmful health effects of environmental hazards; however, there is limited research related to perceptions of risk among individuals who live near such environmental hazard sites. We explored the association between individual-level perception of community safety and respiratory illness among low-income, minority adults who live in a region with routine poor air quality exacerbated by the emissions of a nearby freight railyard.
\end{abstract}

Methods: Interview-administered household surveys were collected (87\% response rate; $n=965$ ) in English/ Spanish from varying distances surrounding a freight railyard (analytic total $n=792$ : nearest region $n=215$, middle $n=289$, farthest $n=288$ ). Illness outcome was an affirmative response to doctor-diagnosed asthma, bronchial condition, emphysema, COPD, or prescribed-inhaler usage. Respiratory symptoms outcome was an affirmative response to chronic cough, chronic mucus, or wheezing. The independent variable was perceived community safety.

Results: Outcome prevalences were similar across environmental hazard regions; 205 (25.9\%) were diagnosed-illness cases and 166 (21.0\%) diagnosis-free participants reported symptoms. Nearly half (47.5\%) of participants reported lack of perceived community safety, which was associated with environmental hazard region $(p<0.0001)$. In multivariable logbinomial regression models adjusting for covariables (age, gender, race/ethnicity, smoking status, smoke exposure, residential duration, and distance from the railyard) respiratory illness diagnosis was associated with lack of perceived community safety $(P R=1.39 ; 95 \% \mathrm{Cl} 1.09,1.76)$. Sensitivity analyses showed a non-significant but increasing trend in the strength of association between safety perceptions and illness diagnoses with closer proximity to the railyard.

Conclusions: Our findings contribute to the literature that individuals' perceptions of community safety are associated with adverse respiratory health among a population living in high air pollution exposure areas.

Keywords: Community health, Asthma, Chronic obstructive pulmonary disease (COPD), Violence, Perceptions, Community safety

\section{Background}

Exposure to social stressors and environmental hazards are more common and are elevated in low-income, minority, urban communities [1-5]. While it is well established that higher polluting industries are more likely to settle near low income communities (or that low income

\footnotetext{
* Correspondence: karthur@llu.edu

${ }^{1}$ School of Public Health, Center for Community Resilience, Loma Linda University, 24951 N. Circle Drive, Nichol Hall, room 1401, Loma Linda, CA 92350, USA

Full list of author information is available at the end of the article
}

communities develop nearby due to lower housing costs) $[6,7]$, there is also growing evidence that suggests that social disadvantage (e.g. exposure to community violence) magnifies the effects from environmental hazards on adverse health outcomes [8-15].

Stress appears to not only have a direct effect on health outcomes, but may also influence susceptibility to or be influenced by other determinants of health [16]. Animal studies support the biologic plausibility that chronic social stress leads to greater susceptibility of respiratory health issues due to air pollution exposure

(c) The Author(s). 2018 Open Access This article is distributed under the terms of the Creative Commons Attribution 4.0 International License (http://creativecommons.org/licenses/by/4.0/), which permits unrestricted use, distribution, and reproduction in any medium, provided you give appropriate credit to the original author(s) and the source, provide a link to the Creative Commons license, and indicate if changes were made. The Creative Commons Public Domain Dedication waiver (http://creativecommons.org/publicdomain/zero/1.0/) applies to the data made available in this article, unless otherwise stated. 
[17]. Because the effects of air pollution on respiratory health, especially asthma, have been found to be greater in low socio-economic status (SES) populations, psychosocial stress has been suggested to also have an effect on this relationship [12, 18]; this suggests that those who are exposed to both air pollution and social stress are more susceptible to the adverse health effects of air pollution than those who are singly exposed [11, 19].

Residential community violence/crime or an overall feeling of living in an unsafe neighborhood are measurable factors of social disadvantage. Neighborhood-level violence/crime, as a measure for psychosocial stress, is a suggested risk factor in the pathophysiology of asthma incidence and morbidity [20,21]. Perceived stress may also be a risk factor for adult-onset asthma [22] and has been strongly associated with increased asthma morbidity [23]. Exposure to violence, measured individually, has been consistently associated with worsening asthma morbidity in children [10, 24, 25], risk of asthma among children [11, 26], and asthma symptom severity in adults [27, 28]. In addition, the Adverse Childhood Experiences Study has found a graded and significant relationship between exposure to violence/trauma during childhood and incidence and morbidity of chronic obstructive pulmonary disease (COPD) as an adult [29].

Within the context of environmental hazards research, the effects on adverse respiratory health from air pollution may have become diluted in analyses when whole communities with healthy individuals are investigated. For instance, a greater and more pertinent effect on adverse health may be found when instead investigating vulnerable populations from both perspectives - either as environmentally vulnerable (e.g. those living very near high traffic roads or goods movement traffic) or as socially vulnerable (e.g. those who are more exposed to psychosocial stressors) [30,31]. Research on the effects of social disadvantage and ambient air pollution on respiratory health is specifically lacking in adult populations living in the context of this type of intersection (social and environmental vulnerability), as is the case for minority populations living near a major pollutant emission source, such as a freight railyard.

The inland region of Southern California offers such a yet to be studied context. In a region well known for routine poor air quality [32], it is also home to the San Bernardino Railyard (SBR), a major stationary, diesel particulate emitting matter source [7], located adjacent to a densely populated low income community. This SBR region is on a shortlist of widely recognized full-fledged inland ports in the U.S. with diesel-powered locomotives and trucks operating 24/7 [7,33]. According to the California Air Resources Board Health Risk Assessment report, the diesel particulate matter emissions within one mile from the SBR are estimated at about 22 tons per year, which represent $66 \%$ of the total on-site and off-site emissions combined [33]. Of 18 railyards in California, the SBR has the highest population exposure to railyard emissions due to the highest residential density near the railyard [7]. Moreover, San Bernardino County residents continuously exhibit higher chronic disease morbidity than California state counterparts, including asthma [34]. San Bernardino County is one of the most underfunded regions in the state [35]. It's economic hardship became well known after the city filed for bankruptcy in 2012 [36]. Nearer to the SBR, the city of San Bernardino has the third largest number of gang members in the U.S. [35]. In 2012, metropolitan San Bernardino had more than twice the violent crime and murder offenses per population size compared to neighboring Los Angeles [37] and the city in past decades has consistently been in the top 25 most violent cities in the U.S. [38]. Many other social determinants from economic to neighborhood segregation support evidence that this is a socially and environmentally vulnerable population exhibiting varying levels of social deprivation [35].

Households from the San Bernardino city area directly adjacent to, and at varying distances from, this goods movement network were included in the Environmental Railyard Research Impacting Community Health (ENRRICH) Project, a mixed-methods, community-based participatory research study. During the community engagement phase of the research project, community members expressed that most of their immediate concerns centered on issues related to law enforcement, street lighting and repair, trees and greenery, and a violence and unemployment ripple effect [39]; in other words, social and neighborhood health factors, as opposed to personal health concerns such as asthma due to the nearby emitting railyard. This paper explores follow-up survey results of adult residents. The goal was to explore if the social stressor related concerns community members had (i.e. perceived community safety) were related to adverse respiratory health outcomes. Thus, in a predominantly low-income, minority, environmentally vulnerable adult population, this paper aims to determine (1) the extent to which this population perceives their community as unsafe and (2) to what degree such perceptions affect respiratory illness.

\section{Methods \\ Study population}

The ENRRICH Project was conducted in 2011-2012 by Loma Linda University (LLU) researchers and a local community partner organization (Center for Community Action and Environmental Justice), using community-based participatory methods to reach the hard-to-access, low income, predominantly Latino population living near the San Bernardino Railyard (SBR). The purpose was to characterize the community health burden of disease in the 
residential areas near the SBR, an inland goods movement network with routine, severe ambient air pollution problems. To account for the seasonal variation in local air quality, ENRRICH investigators conducted two cross-sectional waves of data collection, one in the summer of 2011 and a second wave in the winter-spring of 2012.

Three sampling regions $(\mathrm{A}, \mathrm{B}$, and $\mathrm{C})$ surrounding the SBR were surveyed using a community-based participatory research (CBPR) approach; a CBPR approach incorporates (in our case) carefully trained community members alongside research investigators (who are often academic) during development, administration, and analysis of a study/project. The survey data were collected from adults (ages 18 years and older) present in the household at the time of survey. The location and spatial configuration of the sampling regions are depicted in Fig. 1. The three regions were designed to model decreasing levels of air pollution exposure (derived through computer-based air dispersion modeling based on the California Air and Resource Board's Health Risk Assessment) in relation to the railyard, from highest (A) to lowest $(\mathrm{C})$. We will refer to these three sampling or residential regions as environmental hazard regions.

Region A was defined by delineating a 350-m buffer around the perimeter of the railyard facility and every house within region A was considered for interviewing. Within sampling regions $B$ and $C$, households were randomly selected - ENRRICH investigators used digital street and cadastral maps of the target neighborhoods and assigned households for interviews using a GIS-based random number generator tool. Sampling methodology with regards to air dispersion modelling is discussed more in depth elsewhere [35]. For safety reasons, interviewing was conducted only during daylight hours; this included early evenings and weekends. There were 965 complete interviews (300 in region $A, 338$ in region $B, 324$ in region $C$ ) and 792 had complete information for all analyzed variables thus constituting our analytic study population (215 in region A, 289 in region B, 288 in region C).

\section{Survey}

LLU investigators utilized a CBPR approach to the study design with a mixed methods research methodology to develop the survey instrument. To gather information in a culturally competent and linguistically-appropriate manner, the survey instrument was developed based on mixed methods research exploring the perceived needs and challenges of the affected population, as well as from existing literature. The process included internal technical discussions with the community-based partners and direct community feedback in the form of in depth key informant interviews and focus groups. This mixed-methods process helped to identify relevant questions (from both scientific and community perspectives)

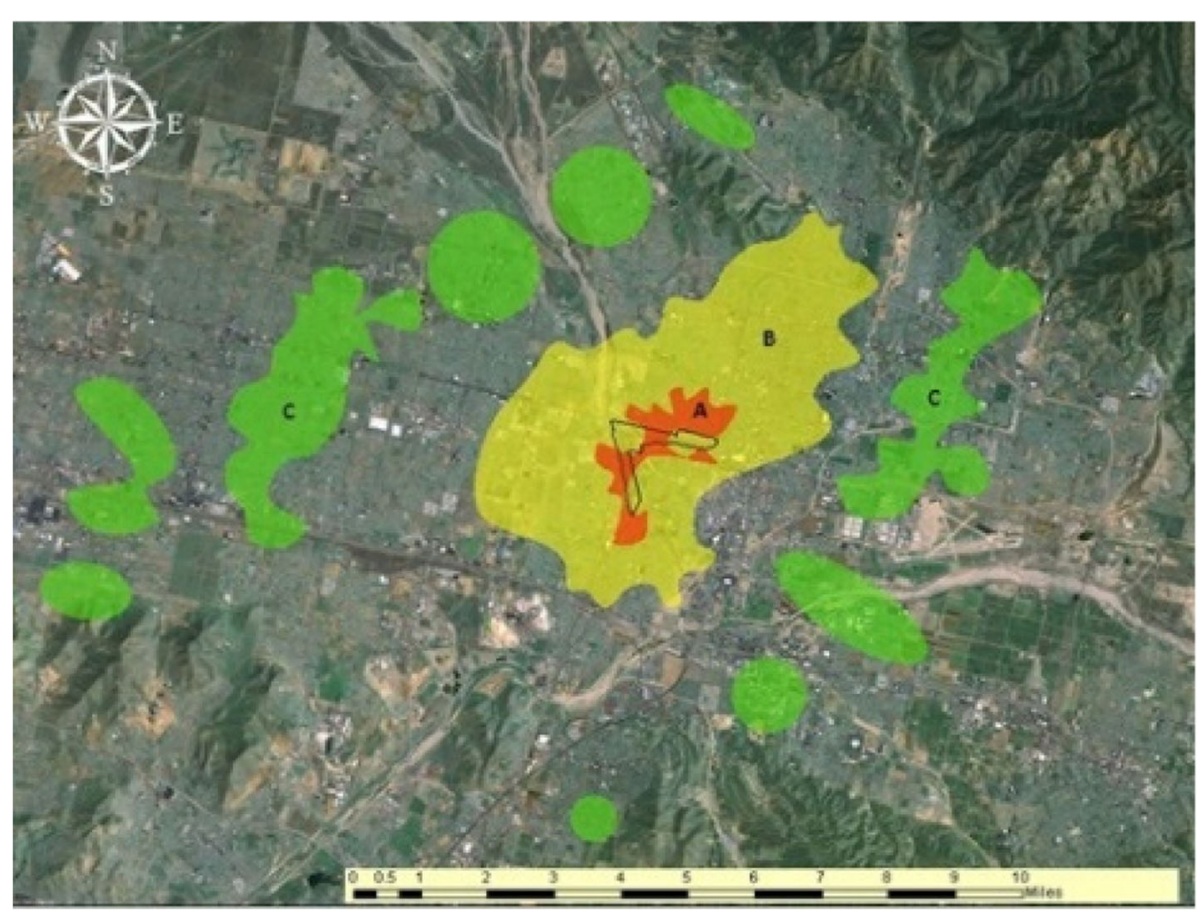

Fig. 1 Geography of the BNSF San Bernardino Railyard in southwestern San Bernardino County, inland Southern California. Railyard outlined in black. Sampling regions (also referred to as, environmental hazard regions) from which households were selected: A (nearest region, red); B (middle region, yellow); and C (farthest region, green) 
to incorporate into the survey, such as lived experiences as well as attitudes and perceptions regarding the health impacts from residential proximity to the SBR and is reported elsewhere [39].

Once developed, the survey was translated to Spanish and pilot tested. It consists of several sections including questions pertaining to demographics, description of household socioeconomic status, history of doctor-diagnosed illnesses, respiratory symptoms, hearing impairment, use of medications, health care utilization, occupational and residential histories, smoking status/history, indoor sources of air pollution, and perceptions of their community (Additional file 1). Survey administration, in a personal interview format to address low reading levels, was delivered by trained, bi-lingual community health workers (as part of our CBPR approach) from the study's local community partner, a non-profit environmental justice organization [40].

The research study was approved by Loma Linda University Institutional Review Board (IRB \#5110054). All participants provided informed written consent prior to participation in the study.

\section{Perceived community safety stressor}

The perceived community safety independent variable used in this paper is a construct created from two survey items pertaining to community safety on the ENRRICH household survey: "I feel safe walking in my community, day or night." and "Violence or crime is not a problem in my community." Participants responded on a 5-point Likert scale from strongly agree to strongly disagree. For ease of interpretation, responses to each of the two statements were dichotomized. A response of "disagree" or "strongly disagree" was considered as the exposure (i.e. lack of perceived community safety as the exposure). We then created a dichotomous perceived community safety construct variable to capture any perception of lack of community safety. The exposed category was defined as responding "disagree" or "strongly disagree" to either one of the above two statements.

\section{Respiratory illness outcomes}

Two respiratory health endpoints were assessed in this study: self-reported doctor-diagnosed respiratory illness and self-reported chronic respiratory symptoms. Both outcome variables were created constructs from the ENRRICH household survey.

The self-reported doctor-diagnosed respiratory illness outcome was created from survey questions that asked if the participant ever had a doctor-diagnosis of asthma, a bronchial condition, emphysema, or chronic obstructive pulmonary disease (COPD). Pilot testing indicated that some respondents had low health care literacy and did not clearly understand the term "diagnosis." For this reason, use of an inhaler ("Do you use a physician-prescribed inhaler?") was asked to determine if there were participants who were prescribed medication for respiratory conditions, but said "no" to ever being diagnosed with a chronic respiratory illness. Participants were counted as a respiratory illness case if they had replied "yes" to any one of the respiratory illnesses or to use of a prescribed inhaler.

Because some participants may not have been diagnosed yet with a respiratory illness due to low-income status and/or limited health care access, we also included self-reported respiratory symptoms as an outcome for analysis among the subset of the participants who did not report a respiratory illness. The self-reported chronic respiratory symptoms outcome includes current chronic coughing and current chronic mucus (defined as having the symptom "on most days for three months or more out of the year"), and ever having wheezing not due to a cold. Participants responded a dichotomous yes/no to these questions. Participants were counted as a respiratory symptoms case if they had replied "yes" to any one of the three symptoms.

\section{Statistical analyses}

For descriptive statistics, we computed frequencies for categorical variables and mean and standard deviation for continuous variables (i.e. age). For bivariate associations, we computed chi-square tests for categorical variables and a two-sample t-test for the variable age, which was normally distributed.

We studied the association between perceived lack of community safety stressors and the outcomes (respiratory illness and respiratory symptoms constructs) using multivariable log-binomial regression models which allowed for the calculation of prevalence ratios (PR) and 95\% confidence intervals $(95 \% \mathrm{CI})$ [41]. Covariates were a priori selected based on relevance in the literature and availability within the ENRRICH dataset. The minimally-adjusted model included risk factors of the respiratory disease outcome [42-45]: age, gender (male, female), race/ethnicity (Hispanic/Latino; black/African-American; white, Asian, other), smoking status (currently, past, never), having lived with a smoker for more than six months as an adult (currently, past, never), duration at current residence $(<1$ year, $1-10$ years, $\geq 11$ years), and environmental hazard exposure region $(\mathrm{A}, \mathrm{B}, \mathrm{C})$. In addition to the minimally-adjusted model variables, the final model added the following individual-level socio-economic status variables: health care insurance (none; private, blue cross, HMO, military or other; Medicare, Medicaid, or Medi-cal), employment status (unemployed; part-time employed, full-time employed, retired or student), and number of people living at the current residence (1-2 people, $3-5$ people, $\geq 6$ people).

We chose not to collapse the covariate duration at current residence for less than one year, despite a small 
count, to reflect a possible biological effect, but interpreted statistics for duration at current residence with caution. Education was not included as a covariate because of its high correlation with unemployment, insurance, and number in household; in addition, adding education to the model did not change the precision of model and did not statistically confound the relationship between the respiratory illness outcome and community safety variable. We considered income as a potential confounder but chose to not include it in the full multi-variable models due to its high number of missing ( $n=93$ missing). To assess its affect in the full multi-variable model, we conducted a sensitivity analysis with income in the full model and found that the main effect between respiratory illness and perceived community safety did not change.

To further describe the association between perceived community safety and respiratory illness, we conducted sensitivity and effect modification analyses by region. Sensitivity analyses included region specific analyses using the same multivariable models stated above. Results are interpreted with caution due to smaller sample sizes. Our effect modification analyses tested multiplicative interaction between the perceived community safety construct and environmental hazard region within the multivariable fully-adjusted model with respiratory illness construct as the outcome. Environmental hazard region was included into the models as a nominal $(\mathrm{A}, \mathrm{B}$, and $\mathrm{C})$ and dichotomous $(\mathrm{A} / \mathrm{B}$ and $\mathrm{C})$ variable. The choice to collapse regions $\mathrm{A}$ and $\mathrm{B}$ was to keep the regions closer to the freight railyard together in comparison to region $\mathrm{C}$, which is the region on the edge of the metropolitan San Bernardino city area.

In our last sensitivity analysis, we tested the association between perceived community safety and respiratory symptoms construct only among the subgroup of individuals who did not report a respiratory illness. SAS version 9.4 was used for all analyses.

\section{Results}

\section{Study population characteristics}

The ENRRICH study population was predominantly Hispanic (76\%), female (68\%), married (58\%) and high school educated or less (61\%). Participants reported having low income, $93 \%$ of the study population reported an average annual household income of less than $\$ 50,000$ with $86 \%$ reporting a household size of three or more persons. Coinciding with a low self-reported average annual household income, $77 \%$ of participants reported having either no health insurance or being covered by Medicaid, Medicare, or Medi-cal. The majority of participants $(94.6 \%)$ had lived at their current residence for more than one year (Table 1 ).

\section{Perceived community safety}

Two-hundred twenty-five (28.4\%) participants reported feeling unsafe walking in their community, 309 (39.0\%) reported violence/crime to be a problem in their community, and 376 (47.5\%) reported a lack of perceived community safety as measured by the construct variable. Of those who reported lack of perceived community safety, $42.0 \%(n=158)$ reported "yes" to both feeling unsafe walking and violence/crime to be a problem in their community.

Those who lacked perceived community safety, as measured by the construct, were more likely to self-report being White, Asian or "other" $(p=0.03)$ and to live nearest to the environmental hazard $(p<0.0001)$ (Table 1$)$.

\section{Respiratory illness outcome}

Two-hundred five participants (25.9\%) were considered as a doctor-diagnosed respiratory illness case as measured by the constructed respiratory illness variable which included inhaler-use. One-hundred ninety (24.0\%) participants reported respiratory illness (asthma, emphysema, chronic bronchitis or COPD). Asthma was the most reported respiratory illness $(n=98)$ followed by a bronchial condition $(n=93)$, COPD $(n=34)$, and emphysema $(n=8)$. Twenty-seven participants $(3.4 \%)$ reported at least two different respiratory illnesses and ninety (11.3\%) participants reported use of a physician-prescribed inhaler. (Table 2). Lastly, of those who reported any respiratory illness, $39.4 \%(n=74)$ also reported use of a prescribed inhaler, the majority of whom reported doctor diagnosis of asthma $(n=58)$.

The proportion of self-reported doctor diagnosed respiratory illness outcome did not differ by environmental hazard (residential) region. Those with self-reported doctor diagnosed respiratory illness outcome were more likely to be non-Hispanic $(p=0.005)$, have some form of health insurance $(p=0.006)$, be a current smoker $(p=0.01)$, single (never married/widowed/divorced) $(p=0.0006)$, or live alone or with one other person $(p=0.0008)$ (Table 1$)$.

Doctor-diagnosis of a respiratory illness as measured by the construct $(p=0.004)$, any doctor-diagnosed respiratory illness (asthma, bronchial condition, emphysema, or COPD $)(p=0.003)$, a doctor-diagnosis of bronchial condition $(p=0.009)$ and prescribed-inhaler use $(\mathrm{p}=0.006)$ were each associated with lack of perceived community safety (Table 2 ).

\section{Log-binomial regression analyses}

The prevalence of participants with a self-reported doctor-diagnosed respiratory illness was $40 \%$ greater among the group of participants who reported lack of perceived community safety ( $\mathrm{PR}=1.39 ; 95 \%$ CI $1.09,1.76)$. The strengths of the associations were similar for both stressor variables, feeling unsafe walking $(\mathrm{PR}=1.37$; $95 \%$ 
Table 1 Study population characteristics by respiratory illness status and by lack of perceived community safety construct

\begin{tabular}{|c|c|c|c|c|c|c|c|}
\hline \multirow[t]{4}{*}{ Variable } & \multirow{4}{*}{$\begin{array}{l}\text { Total } \\
(n=792) \\
\mathrm{n}(\%)\end{array}$} & \multicolumn{3}{|c|}{ Respiratory IIIness } & \multicolumn{3}{|c|}{ Lack of Community Safety } \\
\hline & & \multirow{3}{*}{$\begin{array}{l}\text { Yes } \\
(n=205) \\
\mathrm{n}(\%)\end{array}$} & \multirow{3}{*}{$\begin{array}{l}\text { No } \\
(n=587) \\
n(\%)\end{array}$} & \multirow{3}{*}{$p$-value } & \multirow{3}{*}{$\begin{array}{l}\text { Yes } \\
(n=376) \\
\text { n (\%) }\end{array}$} & \multirow{3}{*}{$\begin{array}{l}\text { No } \\
(n=416) \\
\mathrm{n}(\%)\end{array}$} & \multirow{3}{*}{$p$-value } \\
\hline & & & & & & & \\
\hline & & & & & & & \\
\hline Age, mean $\pm S D$ & $44.4 \pm 14.3$ & $46.3 \pm 14.8$ & $43.8 \pm 14.0$ & $0.03^{*}$ & $44.6 \pm 14.1$ & $44.3 \pm 14.4$ & 0.77 \\
\hline \multicolumn{8}{|l|}{ Gender } \\
\hline Female & $540(68.2)$ & $138(67.3)$ & $402(68.5)$ & \multirow[t]{2}{*}{0.78} & $262(69.7)$ & $278(66.8)$ & \multirow[t]{2}{*}{0.39} \\
\hline Male & $252(31.8)$ & $67(32.7)$ & $185(31.5)$ & & $114(30.3)$ & $138(33.2)$ & \\
\hline \multicolumn{8}{|l|}{ Employment status } \\
\hline Unemployed & $368(46.5)$ & $89(43.4)$ & $279(47.5)$ & \multirow[t]{2}{*}{0.31} & $176(46.8)$ & $192(46.2)$ & \multirow[t]{2}{*}{0.85} \\
\hline Employed, student or retired & $424(53.5)$ & $116(56.6)$ & $308(52.5)$ & & $200(53.2)$ & $224(53.8)$ & \\
\hline \multicolumn{8}{|l|}{ Race/Ethnicity } \\
\hline Hispanic/Latino & $606(76.5)$ & $140(68.3)$ & $466(79.4)$ & \multirow[t]{3}{*}{$<0.01^{*}$} & $279(74.2)$ & $327(78.6)$ & \multirow[t]{3}{*}{$0.03^{*}$} \\
\hline African-American/Black & $85(10.7)$ & $31(15.1)$ & $54(9.2)$ & & $37(9.8)$ & $48(11.5)$ & \\
\hline White, Asian, Other & $101(12.8)$ & $34(16.6)$ & $67(11.4)$ & & $60(16.0)$ & $41(9.9)$ & \\
\hline \multicolumn{8}{|l|}{ Education } \\
\hline$\leq$ Grade school & $225(28.7)$ & $66(32.7)$ & $159(27.4)$ & \multirow[t]{4}{*}{0.50} & $113(30.5)$ & $112(27.1)$ & \multirow[t]{4}{*}{0.26} \\
\hline High School & $253(32.3)$ & $59(29.2)$ & $194(33.4)$ & & $122(33.0)$ & $131(31.7)$ & \\
\hline Some college, vocational, business, or trade & $232(29.6)$ & $58(28.7)$ & $174(29.9)$ & & $108(29.2)$ & $124(30.0)$ & \\
\hline$\geq$ Associates degree & $73(9.3)$ & $19(9.4)$ & $54(9.3)$ & & $27(7.3)$ & $46(11.1)$ & \\
\hline \multicolumn{8}{|l|}{ Health care insurance } \\
\hline None & $355(44.8)$ & $73(35.6)$ & $282(48.0)$ & $<0.01^{*}$ & $178(47.3)$ & $177(42.5)$ & 0.29 \\
\hline Private, Blue Cross, $\mathrm{HMO}$, military, or other & $183(23.1)$ & $51(24.9)$ & $132(22.5)$ & & $87(23.1)$ & $96(23.1)$ & \\
\hline Medicare/caid/cal & $254(32.1)$ & $81(39.5)$ & $173(29.5)$ & & $111(29.5)$ & $143(34.4)$ & \\
\hline Ever regularly smoked cigarettes, cigars, or a pi & & & & & & & \\
\hline Current smoker & $153(19.3)$ & $54(26.3)$ & $99(16.9)$ & $0.01^{*}$ & $79(21.0)$ & $74(17.8)$ & 0.51 \\
\hline Past smoker & $92(11.6)$ & $20(9.8)$ & $72(12.3)$ & & $42(11.2)$ & $50(12.0)$ & \\
\hline Never smoker & $547(69.1)$ & $131(63.9)$ & $416(70.9)$ & & $255(67.8)$ & $292(70.2)$ & \\
\hline As an adult, lived for $>6$ mo. with someone wh & smoked & & & & & & \\
\hline Yes, currently & $31(3.9)$ & $12(5.9)$ & $19(3.2)$ & 0.07 & $16(4.3)$ & $15(3.6)$ & 0.45 \\
\hline Yes, in the past & $184(23.2)$ & $55(26.8)$ & $129(22.0)$ & & $94(25.0)$ & $90(21.6)$ & \\
\hline No & $577(72.9)$ & $138(67.3)$ & 439 (74.8) & & $266(707)$ & $311(74.8)$ & \\
\hline Average annual household income & & & & & & & \\
\hline$<\$ 10,000$ & $214(30.6)$ & $55(30.9)$ & $159(30.5)$ & 0.82 & $111(32.4)$ & $103(28.9)$ & 0.11 \\
\hline$\$ 11,000-\$ 19,000$ & $175(25.0)$ & $49(27.5)$ & $126(24.2)$ & & $96(28.0)$ & $79(22.2)$ & \\
\hline$\$ 20,000-\$ 29,000$ & $138(19.7)$ & $31(17.4)$ & $107(20.5)$ & & $65(19.0)$ & $73(20.5)$ & \\
\hline$\$ 30,000-\$ 49,000$ & $125(17.9)$ & $30(16.9)$ & $95(18.2)$ & & $53(15.4)$ & $72(20.2)$ & \\
\hline$>\$ 50,000$ & $47(6.7)$ & $13(7.3)$ & $34(6.5)$ & & $18(5.2)$ & $29(8.2)$ & \\
\hline Marital Status & & & & & & & \\
\hline Never married/ widowed/divorced & $328(41.5)$ & $106(51.7)$ & $222(38.0)$ & $<0.001^{*}$ & $166(44.4)$ & $162(38.9)$ & 0.12 \\
\hline Married/live together & $462(58.5)$ & $99(48.3)$ & $363(62.0)$ & & $208(55.6)$ & $254(61.1)$ & \\
\hline People in household & & & & & & & \\
\hline 1-2 people & 109 (13.8) & $41(20.0)$ & 68 (11.6) & $<0.001^{*}$ & $59(15.7)$ & $50(12.1)$ & 0.30 \\
\hline 3-5 people & $430(54.3)$ & $116(56.6)$ & $314(53.5)$ & & $202(53.7)$ & $228(54.8)$ & \\
\hline 6 or more people & $253(31.9)$ & $48(23.4)$ & $205(34.9)$ & & $115(30.6)$ & $138(33.1)$ & \\
\hline
\end{tabular}


Table 1 Study population characteristics by respiratory illness status and by lack of perceived community safety construct (Continued)

\begin{tabular}{|c|c|c|c|c|c|c|c|}
\hline \multirow[t]{4}{*}{ Variable } & \multirow{4}{*}{$\begin{array}{l}\text { Total } \\
(n=792) \\
\text { n (\%) }\end{array}$} & \multicolumn{3}{|c|}{ Respiratory Illness } & \multicolumn{3}{|c|}{ Lack of Community Safety } \\
\hline & & \multirow{3}{*}{$\begin{array}{l}\text { Yes } \\
(n=205) \\
n(\%)\end{array}$} & \multirow{3}{*}{$\begin{array}{l}\text { No } \\
(n=587) \\
\text { n (\%) }\end{array}$} & \multirow{3}{*}{$p$-value } & \multirow{3}{*}{$\begin{array}{l}\text { Yes } \\
(n=376) \\
n(\%)\end{array}$} & \multirow{3}{*}{$\begin{array}{l}\text { No } \\
(n=416) \\
\text { n (\%) }\end{array}$} & \multirow{3}{*}{$p$-value } \\
\hline & & & & & & & \\
\hline & & & & & & & \\
\hline \multicolumn{8}{|c|}{ Duration at current residence } \\
\hline $11+$ years & $213(26.9)$ & $57(27.8)$ & $156(26.6)$ & 0.09 & $105(27.9)$ & $108(26.0)$ & 0.14 \\
\hline $1-10$ years & $536(67.7)$ & $143(69.8)$ & $393(66.9)$ & & $245(65.2)$ & $291(69.9)$ & \\
\hline$<1$ year & $43(5.4)$ & $5(2.4)$ & $38(6.5)$ & & $26(6.9)$ & $17(4.1)$ & \\
\hline \multicolumn{8}{|c|}{ Environmental hazard region } \\
\hline A - closest to SBR & $215(27.1)$ & $50(24.4)$ & $165(28.1)$ & 0.35 & $131(34.8)$ & $84(20.2)$ & $<0.0001^{*}$ \\
\hline B - intermediate & $289(36.5)$ & $83(40.5)$ & $206(35.1)$ & & $136(36.2)$ & $153(36.8)$ & \\
\hline C - farthest away & 288 (36.4) & $72(35.1)$ & 216 (36.8) & & $109(29.0)$ & $179(43.0)$ & \\
\hline
\end{tabular}

*Denotes a statistically significant $p$-value for chi-square statistic (or t-test for the variable age) at alpha-level $\leq 0.05$

$\%=$ column percent; SD = standard deviation; $\mathrm{n}(\%)$ for categorical variables and mean \pm SD for continuous variables (i.e. age); SBR = San Bernardino Railyard

CI 1.07, 1.74) or perceiving violence/crime to be a problem in their community (PR $=1.36 ; 95 \% \mathrm{CI} 1.07,1.72)$, compared to the community safety construct variable (Table 3). In the fully-adjusted model with community safety construct as the independent variable (Table 3), duration of residence for less than one year and reporting Medicare, Medicaid, or Medi-cal health insurance were also associated with a higher prevalence of self-reported respiratory illness $(\mathrm{PR}=0.38,95 \% \mathrm{CI}$ $0.17,0.87$ versus $1-10$ years; $P R=1.45,95 \%$ CI 1.10 , 1.91 versus no health insurance).

We found an increasing, but non-significant, trend in the strength of associations between lack of perceived community safety and respiratory illness as residents lived closer to the freight railyard (Table 3). For subpopulation regions $\mathrm{A} \& \mathrm{~B}$, the association between lack of perceived community safety and respiratory illness persisted ( $\mathrm{PR}=1.52,95 \%$ CI 1.12, 2.07), although the confidence interval also overlaps with that of the total population (Table 3). The multiplicative interaction term between the perceived community safety construct and environmental hazard region was not significant in the fully-adjusted model for the total population.

\section{Respiratory symptoms outcome}

Among the subgroup of participants who did not report a respiratory illness $(n=587), 166$ participants $(29.0 \%$ or $21.0 \%$ of the total population) reported respiratory symptoms measured as a construct. Ninety-one (15.6\%) reported chronic cough, 85 (14.6\%) reported chronic mucus, and $77(13.4 \%)$ reported wheezing symptoms not due to a cold. Of those who reported a respiratory symptom, $11.1 \%$ $(n=65)$ reported two or more symptoms (Table 2$)$.

The proportion of self-reported respiratory symptoms outcome did not differ by environmental hazard (residential) region. Those who reported respiratory symptoms were more likely to have Medicare, Medicaid, or Medi-cal insurance $(p=0.016)$, be a current smoker $(p=0.014)$, and have lived with a smoker in the past $(p=0.002)$. Reporting two or more symptoms was associated with lack of perceived community safety $(p=0.032)$ (Table 2$)$. In the fully-adjusted log-binomial model, lack of perceived community safety was not associated with the prevalence of respiratory symptoms $(\mathrm{PR}=1.14,95 \%$ CI $0.89,1.46)$.

\section{Discussion}

To our knowledge, this is the first study to provide insight into the possible effect of community perceptions of safety on respiratory illness among adult, low-income, minority community members who were also environmentally vulnerable due to living in a region with routine poor air quality and with the additional exposure to a major pollutant source. We found a strong independent association between lack of perceived community safety and doctor diagnosed respiratory illness. Perceiving your community to be unsafe, arguably a stressful feeling, increased the likelihood of having been diagnosed with a respiratory illness by $40 \%$. This effect was independent from other known factors associated with respiratory illness, such as age, tobacco exposure, low socio-economic status, or even distance from a diesel emission particulate matter air polluter. Although no association was found between perceived community safety and respiratory symptoms among the un-diagnosed population, these 166 participants with symptoms but no respiratory illness (21\% of the total population) may represent future diagnosed respiratory illness cases in this population. Our findings are in line with others who have found that psychosocial stressors, such as perceived community safety, may contribute to chronic stress which in turn may contribute to the development $[29,46]$ and/or exacerbations $[23,28]$ of chronic respiratory illnesses, including asthma and COPD. 
Table 2 ENRRICH Study population respiratory illness prevalence by perceived lack of community safety construct

\begin{tabular}{|c|c|c|c|c|}
\hline & \multirow[t]{2}{*}{ Total } & \multicolumn{3}{|c|}{ Lack of perceived community safety construct } \\
\hline & & Yes & No & $p$-value \\
\hline \multicolumn{5}{|l|}{$\begin{array}{l}\text { Respiratory illness variables } \\
\text { Among total study population }\end{array}$} \\
\hline & $\begin{array}{l}n=792 \\
n(\%)\end{array}$ & $\begin{array}{l}n=376 \\
n(\%)\end{array}$ & $\begin{array}{l}n=416 \\
n(\%)\end{array}$ & \\
\hline \multicolumn{5}{|l|}{ Respiratory IIIness Construct ${ }^{a}$} \\
\hline Yes & $205(25.9)$ & $115(30.6)$ & $90(21.6)$ & $<0.01^{*}$ \\
\hline No & $587(74.1)$ & $261(69.4)$ & $326(78.4)$ & \\
\hline \multicolumn{5}{|c|}{ Doctor-diagnosed asthma, bronchial condition, emphysema, or COPD } \\
\hline Yes & $190(24.0)$ & $108(28.7)$ & $82(19.7)$ & $<0.01^{*}$ \\
\hline No & $602(76.0)$ & $268(71.3)$ & $334(80.3)$ & \\
\hline \multicolumn{5}{|c|}{ Ever doctor-diagnosed respiratory illnesses (not mutually exclusive): } \\
\hline Asthma & $98(12.4)$ & $52(13.8)$ & $46(11.1)$ & 0.24 \\
\hline Bronchial condition & $93(11.7)$ & $56(14.9)$ & $37(8.9)$ & $<0.01^{*}$ \\
\hline Emphysema & $8(1.0)$ & $6(1.6)$ & $2(0.5)$ & 0.12 \\
\hline COPD & $34(4.3)$ & $21(5.6)$ & $13(3.1)$ & 0.09 \\
\hline Two or more of the above & $27(3.4)$ & $17(4.5)$ & $10(2.4)$ & 0.10 \\
\hline \multicolumn{5}{|l|}{ Medication Use } \\
\hline Prescribed-inhaler use & $90(11.3)$ & $55(14.7)$ & $35(8.4)$ & $<0.01^{*}$ \\
\hline \multicolumn{5}{|c|}{$\begin{array}{l}\text { Respiratory Symptoms Variables } \\
\text { Among Respiratory Illness Free Sub-Population }\end{array}$} \\
\hline & $\begin{array}{l}n=587 \\
\mathrm{n}(\%)\end{array}$ & $\begin{array}{l}n=261 \\
n(\%)\end{array}$ & $\begin{array}{l}n=326 \\
n(\%)\end{array}$ & \\
\hline \multicolumn{5}{|c|}{ Respiratory Symptoms Construct ${ }^{\mathrm{b}}$} \\
\hline Yes & $166(29.0)$ & $79(31.1)$ & $87(27.3)$ & 0.32 \\
\hline No & $407(71.0)$ & $175(68.9)$ & $232(72.7)$ & \\
\hline \multicolumn{5}{|l|}{ Chronic Cough } \\
\hline Yes & $91(15.6)$ & $47(18.1)$ & $44(13.5)$ & 0.13 \\
\hline No & $494(84.4)$ & $213(81.9)$ & $281(86.5)$ & \\
\hline \multicolumn{5}{|l|}{ Chronic Mucus } \\
\hline Yes & $85(14.6)$ & $43(16.5)$ & $42(13.1)$ & 0.24 \\
\hline No & $496(85.4)$ & $217(83.5)$ & $279(86.9)$ & \\
\hline \multicolumn{5}{|l|}{ Ever had wheezing } \\
\hline Yes & $77(13.4)$ & $40(15.8)$ & $37(11.6)$ & 0.15 \\
\hline No & $496(86.6)$ & $214(84.2)$ & $282(88.4)$ & \\
\hline \multicolumn{5}{|l|}{ Two or more of the above } \\
\hline Yes & $65(11.1)$ & $37(14.2)$ & $28(8.6)$ & $0.03^{*}$ \\
\hline No & $522(88.9)$ & $224(85.8)$ & $298(91.4)$ & \\
\hline
\end{tabular}

*Denotes a statistically significant $p$-value at alpha-level $\leq 0.05$ from chi-square statistic

${ }^{a}$ Construct created from survey questions asking if participant had doctor-diagnosed respiratory illness (asthma, bronchial condition, emphysema, or COPD) or used a prescribed-inhaler

${ }^{b}$ Construct created from survey questions asking if participant had chronic respiratory symptoms (chronic cough, chronic mucus, or ever had wheezing not due to a common cold)

Chronic stress is known to affect the immune and pro-inflammatory systems, which are suspected to be a part of the etiology of asthma [17, 22, 47-49].

Studies of the effects of psychosocial stress, including exposure to violence $[11,24,26,28]$, on respiratory health have largely been conducted in children [10, 12, 13]. To our knowledge, this rigorously designed cross-sectional study of individually-measured, perceived lack of community safety on respiratory health among a socially- and environmentally- vulnerable adult population is the first of its kind. Our results are in line with a broader body of literature that supports evidence for the association between 
Table 3 Log-binomial regression modeling of association between perceived community safety stressors and self-reported doctordiagnosed respiratory illness

\begin{tabular}{|c|c|c|c|c|c|c|}
\hline \multirow[t]{2}{*}{ Independent variable } & \multicolumn{2}{|l|}{ Crude model } & \multicolumn{2}{|c|}{ Minimally-adjusted model } & \multicolumn{2}{|c|}{ Fully-adjusted model } \\
\hline & PR $(95 \% \mathrm{Cl})$ & $p$-value & PR $(95 \% \mathrm{Cl})$ & $p$-value & PR $(95 \% \mathrm{Cl})$ & $p$-value \\
\hline \multicolumn{7}{|l|}{ Total Population } \\
\hline "I do not feel safe walking in my community, day or night." & $1.31(1.02,1.67)$ & $0.03^{*}$ & $1.34(1.05,1.71)$ & $0.02^{*}$ & $1.37(1.07,1.74)$ & $0.01^{*}$ \\
\hline "Violence or crime is a problem in my community." & $1.38(1.09,1.74)$ & $<0.01^{*}$ & $1.34(1.06,1.70)$ & $0.02^{*}$ & $1.36(1.07,1.72)$ & $0.01^{*}$ \\
\hline Lack of perceived community safety construct & $1.41(1.11,1.79)$ & $<0.01^{*}$ & $1.39(1.10,1.77)$ & $<0.01^{*}$ & $1.39(1.09,1.76)$ & $<0.01^{*}$ \\
\hline \multicolumn{7}{|l|}{ Region A Only } \\
\hline Lack of perceived community safety construct & $1.83(1.03,3.23)$ & $0.04^{*}$ & $1.98(1.09,3.58)$ & $0.02^{*}$ & $1.79(0.97,3.28)$ & 0.06 \\
\hline \multicolumn{7}{|l|}{ Region B Only } \\
\hline Lack of perceived community safety construct & $1.47(1.02,2.12)$ & $0.04^{*}$ & $1.44(1.00,2.07)$ & 0.05 & $1.41(0.98,2.04)$ & 0.06 \\
\hline \multicolumn{7}{|l|}{ Region C Only } \\
\hline Lack of perceived community safety construct & $1.24(0.83,1.85)$ & 0.29 & $1.12(0.75,1.69)$ & 0.58 & $1.14(0.75,1.72)$ & 0.55 \\
\hline \multicolumn{7}{|l|}{ Regions A \& B } \\
\hline "I do not feel safe walking in my community, day or night." & $1.48(1.10,1.98)$ & $<0.01^{*}$ & $1.54(1.15,2.06)$ & $<0.01^{*}$ & $1.59(1.18,2.14)$ & $<0.01^{*}$ \\
\hline "Violence or crime is a problem in my community." & $1.43(1.07,1.91)$ & $0.02^{*}$ & $1.44(1.07,1.93)$ & $0.02^{*}$ & $1.43(1.07,1.93)$ & $0.02^{*}$ \\
\hline Lack of perceived community safety construct & $1.52(1.12,2.07)$ & $<0.01^{*}$ & $1.56(1.15,2.11)$ & $<0.01^{*}$ & $1.52(1.12,2.07)$ & $<0.01^{*}$ \\
\hline
\end{tabular}

past exposure to trauma or violence/adversity, often measured by adverse childhood experiences, and chronic respiratory illness among adults [29, 46, 50-52]; however, these did not adjust for ambient air pollution indicators as was did by adjusting for residential proximity to the railyard.

In addition, in line with our previously published qualitative findings [39] we found that a perception that one's residential community is unsafe was highly prevalent. More than one in four participants reported an unsafe walking environment and more than one in three participants perceived a problem of community violence/crime demonstrating this population to be socially vulnerable. Perception of community safety was, not surprisingly, place-based; the closer the residential region was to the environmental hazard the higher the proportion of participants who reported lack of perceived community safety. Others have reported evidence supporting the causal relationship between upstream, place-based factors and health disparities [20, 31, 49, 53, 54]. Place of residence affects one's perceptions of their surroundings $[55,56]$ and those perceptions may, in turn, affect the individual's health [23, 57-61].

Despite sampling methods to ensure that study participants were selected at varying distances from the railyard, minimal heterogeneity among the various respiratory health outcomes was found. This provided a unique setting to determine the relationship between a place-based, psychosocial determinant and respiratory health in a socially- and environmentally- vulnerable population. The minimal heterogeneity in the respiratory effects from the different environmental hazard (residential sampling) regions allowed us to examine how a psychosocial stressor may contribute to a well-supported [30, 62, 63] causal relationship between ambient air pollution exposure and adverse respiratory health.

The lack of heterogeneity of the respiratory health outcome across the three environmental hazard regions, in addition to the smaller sample size within each region, may have contributed to our null findings when determining if differences exist in the strengths of associations between perceived community safety and respiratory illness in our region-specific sensitivity analyses. On the other hand, these findings could also be due to residual confounding. These unaccounted-for factors (e.g. neighborhood green space or social cohesion) may be different within each residential region, as it has been demonstrated that many low-income, minority study populations have diversity in the range of social disadvantages experienced $[20,64]$. Although non-significant, there exists a clear trend in the strengthening of the association between perceived community safety and respiratory illness as residential distance to the environmental hazard gets smaller. The individual associations within region $\mathrm{A}$ and region $\mathrm{B}$ are borderline significant. In Region A, the prevalence of diagnosed respiratory illness was $80 \%$ higher among the participants who reported lack of perceived community safety compared to those who did not report a lack of perceived community safety. 
Like many other environmental epidemiology studies, our research had some limitations that should be noted. The ENRRICH study was cross-sectional and temporality between psychosocial stressors and respiratory outcomes cannot be determined. More prospective studies in adult, vulnerable populations in this field of research are needed. However, such studies are difficult to conduct due to financial and methodological constraints (tracking bi- and monolingual low-income populations is challenging). Lack of trust in low income neighborhoods may have affected participation; however, given our response rate (87\%) we believe that our CBPR approach may have ameliorated this issue to a large degree. Also potentially affecting participation, some residents may not have been available for interviewing during daylight (working) hours or during early evening daylight hours we used for interviewing. Nevertheless, persons who had spent more time in the environment (resulting in higher risk exposure), and thus were more likely to be available to be interviewed, were of particular interest to this study. Another possible limitation is that both respiratory illness and respiratory symptoms were self-reported and thus subject to information bias; however, a compilation of survey items was explored to capture participants who may have underreported due to health care illiteracy or who may not have had a proper diagnosis due to lack of healthcare access [65].

Despite our limitations, our study has notable strengths. Sampled households were randomly selected. Data was collected by trained bi-lingual community members using a community based participatory research approach [40], which contributed to a high response rate, a notable strength, in a majorly Latino low income target population, with many facing immigration challenges. In addition, it is an advantage to be able to assess psychosocial stressors measured at an individual-level rather than solely relying on census block-level data or use of administrative data. Because the impact of a stressor depends on how one experiences, perceives, and/or interprets the event [47, 61], measuring social stressors at a group-level can result in imprecise assessments of psychosocial stress [10].

Furthermore, the consideration of the community member's concerns as a guide for this analysis, by use of the ENRRICH project's mixed-methods design, lends itself to two strengths. First, we analyzed an identified salient social stressor in this community across a spatially heterogeneous area, which reduced confounding by other hypothesized, less-salient stressors [10]. Secondly, because the experience and 'voices' of community members are crucial for successful place-based interventions [66], this study will be more easily translatable to public health practice in populations that are socially-, economically-and environmentally-vulnerable to adverse health outcomes.

Current research and environmental policy has focused too narrowly on air pollutants alone and should be broadened to take into account the cumulative impact of exposures and vulnerabilities encountered by people who live in low-SES, minority neighborhoods [67]. Our study demonstrates that heterogeneity with regards to social vulnerability (i.e. perceptions of community safety) exists within a low-income, minority population and that a non-chemical, yet place-based factor (i.e. perceptions of community safety) may contribute to adverse chronic respiratory health, aside from exposure to a stationary air pollution emission source alone. Future steps for analyses using the ENRRICH study population will be to test interactions between place-based factors and individual perceptions and to determine relevant social buffers for future intervention strategies.

\section{Conclusions}

In conclusion, when living in a low-income community near a goods movement network with high exposure to diesel emission and in a region with routine poor air quality, the added psychosocial stressor of perceiving your residential community as unsafe increases the likelihood of having a doctor diagnosed chronic respiratory illness. Our finding further supports that when trying to elucidate the effect of air pollution on respiratory health, public health professionals and policy makers must take into account a communities' social, as well as environmental risk, context.

\section{Additional file}

Additional file 1: Project ENRRICH Adult Participant Questionnaire; (survey instrument). (DOCX $58 \mathrm{~kb}$ )

\section{Abbreviations}

CBPR: Community-based participatory research; Cl: Confidence interval; COPD: Chronic obstructive pulmonary disease; ENRRICH

Project: Environmental Railyard Research Impacting Community Health Project; HMO: Health maintenance organization; PR: Prevalence ratio; SBR: San Bernardino Railyard; SES: Socio-economic status

\section{Acknowledgements \\ In memorial: Dr. Samuel Soret 1962 - 2016. \\ Samuel Soret, PhD, MPH, Associate Dean for Research and Executive Director of the Center for Community Resilience at Loma Linda University School of Public Health and a Co-Principal Investigator on this research passed away on 23 August 2016 from a heart attack while on a trip in his home-country of Spain. Dr. Soret faithfully served the School of Public Health for 21 years and lived his motto: "Compassion must fuel everything we do."}

\section{Funding}

This research was funded by the South Coast Air Quality Management District/BP West Coast Products Oversight Committee, LLC, grant \# 659005 and also supported by National Institutes of Health \#1P20MD006988. The funding bodies for our research did not have any role in the study design, collection, analysis, interpretation, or in writing the manuscript. 


\section{Authors' contributions}

KA analyzed and interpreted the data and was the major contributor in writing the manuscript. KA, RS, SK, DS and SM read, edited and approved the final manuscript. Additionally, RS, SK, DS were investigators and SM and SS were co-principle investigators of the study through design, data collection, and analysis. DS provided statistical expertise. RS, SK, and SM contributed to data interpretation and critical revisions. KA and SS contributed to the important critical content and conception of research hypotheses and analytic design.

\section{Ethics approval and consent to participate}

The research study was approved by Loma Linda University Institutional Review Board (IRB \#5110054). All participants provided informed written consent prior to participation in the study.

\section{Consent for publication}

Not applicable.

\section{Competing interests}

The authors declare that they have no competing interests.

\section{Publisher's Note}

Springer Nature remains neutral with regard to jurisdictional claims in published maps and institutional affiliations.

\section{Author details \\ ${ }^{1}$ School of Public Health, Center for Community Resilience, Loma Linda University, 24951 N. Circle Drive, Nichol Hall, room 1401, Loma Linda, CA 92350, USA. ${ }^{2}$ School of Public Health, Center for Nutrition, Health Lifestyle and Disease Prevention, Loma Linda University, Loma Linda, USA. ${ }^{3}$ School of Behavioral Health, Loma Linda University, Loma Linda, USA.}

\section{Received: 23 April 2018 Accepted: 3 August 2018}

\section{Published online: 03 September 2018}

\section{References}

1. Cushing L, Faust J, August LM, Cendak R, Wieland W, Alexeeff G. Racial/ ethnic disparities in cumulative environmental health impacts in California: evidence from a statewide environmental justice screening tool (CalEnviroScreen 1.1). Am J Public Health. 2015;105(11):2341-8.

2. Hipp JR, Lakon CM. Social disparities in health: disproportionate toxicity proximity in minority communities over a decade. Health Place. 2010;16(4): 674-83.

3. IOM. Toward Environmental Justice: Research, Education, and Health Policy Needs. Washington: Institutue of Medicine, Committee on Environmental Justice, Health Sciences Policy Program, Health Sciences Section; 1999.

4. O'Neill MS, Jerrett M, Kawachi I, Levy Jl, Cohen AJ, Gouveia N, Wilkinson P, Fletcher T, Cifuentes L, Schwartz J. Health, wealth, and air pollution: advancing theory and methods. Environ Health Perspect. 2003;111(16): 1861-70.

5. Su JG, Morello-Frosch R, Jesdale BM, Kyle AD, Shamasunder B, Jerrett M. An index for assessing demographic inequalities in cumulative environmental hazards with application to Los Angeles. California Environ Sci Technol. 2009:43(20):7626-34

6. Hirsch JA, Grengs J, Schulz A, Adar SD, Rodriguez DA, Brines SJ, Diez Roux AV. How much are built environments changing, and where?: Patterns of change by neighborhood sociodemographic characteristics across seven $\mathrm{U}$. S. metropolitan areas. Soc Sci Med (1982). 2016;169:97-105.

7. Hricko A, Rowland G, Eckel S, Logan A, Taher M, Wilson J. Global trade, local impacts: lessons from California on health impacts and environmental justice concerns for residents living near freight rail yards. Int J Environ Res Public Health. 2014;1 1(2):1914-41.

8. Clougherty JE, Kubzansky LD. A framework for examining social stress and susceptibility to air pollution in respiratory health. Cien Saude Colet. 2010; 15(4):2059-74.

9. Hicken MT, Adar SD, Diez Roux AV, O'Neill MS, Magzamen S, Auchincloss AH, Kaufman JD. Do psychosocial stress and social disadvantage modify the association between air pollution and blood pressure?: the multi-ethnic study of atherosclerosis. Am J Epidemiol. 2013;178(10):1550-62.

10. Shmool JL, Kubzansky LD, Newman OD, Spengler J, Shepard P, Clougherty JE. Social stressors and air pollution across new York City communities: a spatial approach for assessing correlations among multiple exposures. Environ Health. 2014;13:91.

11. Clougherty JE, Levy JI, Kubzansky LD, Ryan PB, Suglia SF, Canner MJ, Wright RJ. Synergistic effects of traffic-related air pollution and exposure to violence on urban asthma etiology. Environ Health Perspect. 2007;115(8):1140-6.

12. Shankardass K, McConnell R, Jerrett M, Milam J, Richardson J, Berhane K. Parental stress increases the effect of traffic-related air pollution on childhood asthma incidence. Proc Natl Acad Sci U S A. 2009;106(30):12406-11.

13. Islam T, Urman R, Gauderman WJ, Milam J, Lurmann F, Shankardass K, Avol E, Gilliland F, McConnell R. Parental stress increases the detrimental effect of traffic exposure on children's lung function. Am J Respir Crit Care Med. 2011;184(7):822-7.

14. Sadd JL, Pastor M, Morello-Frosch R, Scoggins J, Jesdale B. Playing it safe: assessing cumulative impact and social vulnerability through an environmental justice screening method in the south coast Air Basin, California. Int J Environ Res Public Health. 2011:8(5):1441-59.

15. Hood E. Stress and the city: measuring effects of chronic stress and air pollution. Environ Health Perspect. 2010;118(6):A258.

16. McGovern L, Miller G, Hughes-Cromwick P: Health Policy Brief: The Relative Contribution of Multiple Determinants to Health Outcomes. In: Health Affairs. Edited by Mays G, Lantz P, Lott R: Health Affairs - Robert Wood Johnson Foundation; 2014.

17. Clougherty JE, Rossi CA, Lawrence J, Long MS, Diaz EA, Lim RH, McEwen B, Koutrakis P, Godleski JJ. Chronic social stress and susceptibility to concentrated ambient fine particles in rats. Environ Health Perspect. 2010;1 18(6):769-75.

18. Chen E, Schreier HM, Strunk RC, Brauer M. Chronic traffic-related air pollution and stress interact to predict biologic and clinical outcomes in asthma. Environ Health Perspect. 2008;116(7):970-5.

19. Chi GC, Hajat A, Bird CE, Cullen MR, Griffin BA, Miller KA, Shih RA, Stefanick $\mathrm{ML}$, Vedal S, Whitsel EA, et al. Individual and neighborhood socioeconomic status and the association between air pollution and cardiovascular disease. Environ Health Perspect. 2016;

20. Williams DR, Sternthal M, Wright RJ. Social determinants: taking the social context of asthma seriously. Pediatrics. 2009;123(Suppl 3):S174-84.

21. Wright RJ. Health effects of socially toxic neighborhoods: the violence and urban asthma paradigm. Clin Chest Med. 2006;27(3):413-21.

22. IImarinen P, Tuomisto LE, Kankaanranta H. Phenotypes, risk factors, and mechanisms of adult-onset asthma. Mediat Inflamm. 2015;2015:514868.

23. Wisnivesky JP, Lorenzo J, Feldman JM, Leventhal H, Halm EA. The relationship between perceived stress and morbidity among adult inner-city asthmatics. J Asthma. 2010;47(1):100-4.

24. Wright RJ, Mitchell H, Visness CM, Cohen S, Stout J, Evans R, Gold DR. Community violence and asthma morbidity: the Inner-City asthma study. Am J Public Health. 2004;94(4):625-32.

25. Apter AJ. Communities and health: the case of inner-city violence and asthma. LDI Issue Brief. 2010;16(1):1-4

26. Shankardass K, Jerrett M, Milam J, Richardson J, Berhane K, McConnell R. Social environment and asthma: associations with crime and no child left behind programmes. J Epidemiol Community Health. 2011;65(10):859-65.

27. Fagan J, Galea S, Ahern J, Bonner S, Vlahov D. Relationship of self-reported asthma severity and urgent health care utilization to psychological sequelae of the September 11, 2001 terrorist attacks on the world trade center among new York City area residents. Psychosom Med. 2003;65(6):993-6.

28. Apter AJ, Garcia LA, Boyd RC, Wang X, Bogen DK, Ten Have T. Exposure to community violence is associated with asthma hospitalizations and emergency department visits. J Allergy Clin Immunol. 2010;126(3):552-7.

29. Anda RF, Brown DW, Dube SR, Bremner JD, Felitti VJ, Giles WH. Adverse childhood experiences and chronic obstructive pulmonary disease in adults. Am J Prev Med. 2008;34(5):396-403.

30. Anderson HR, Favarato G, Atkinson RW. Long-term exposure to air pollution and the incidence of asthma: meta-analysis of cohort studies. Air Qual Atmos Health. 2013;6(1):47-56.

31. Diez Roux AV. Neighborhoods and health: what do we know? What should we do? Am J Public Health. 2016;106(3):430-1.

32. State of the Air. In. Edited by American Lung Association. Washington, DC: American Lung Association; 2013. http:/www.stateoftheair.org/2013/states/ california/. Accessed 26 Aug 2018.

33. Castaneda $\mathrm{H}$, et al. Health risk assessment for the BNSF san Bernardino railyard. In. Sacramento: California Air Resources Board; 2008.

34. San Bernardino County Asthma Profile. https://www.cdph.ca.gov/Programs/ CCDPHP/DEODC/EHIB/CPE/Pages/CaliforniaBreathingCountyAsthmaProfiles. aspx. Accessed 26 Aug 2018. 
35. Soret S, Montgomery S, Spencer-Hwang R. Project ENRRICH: a public health assessment of residential proximity to a goods movement railyard in. Loma Linda: Loma Linda University; 2014.

36. City of San Bernardino Chapter 9 Filing. United States Bankruptcy Court Central District of California. http://www.cacb.uscourts.gov/news/city-sanbernardino-chapter-9-filing. Accessed 20 Jan 2018.

37. FBI. California Offenses Known to Law Enforcement by City, 2012. Crime in the United States 2012. Retrieved 19 July, 2017, from https:/ucr.fbi.gov/crime-inthe-u.s/2012/crime-in-the-u.s.-2012/tables/8tabledatadecpdf/table-8-state-cuts/ table_8_offenses_known_to_law_enforcement_by_california_by_city_2012.xls.

38. Michael B. Sauter TCF, Evan Comen: 25 Most Dangerous Cities in America. In: 24/7 Wall St. 247wallst.com; 2017.

39. Spencer-Hwang R, Montgomery S, Dougherty M, Valladares J, Rangel S, Gleason P, Soret S. Experiences of a rail yard community: life is hard. J Environ Health. 2014;77(2):8-17.

40. Spencer-Hwang R, Soret S, Halstead L, Dougherty M, Valladares J, Rangel S, Youssef C, Maldonado-Gamboa T, Montgomery S. Making human subject protection training community responsive: experiences delivering on the community-based participatory research promise. Prog Community Health Partnersh. 2014;8(2):215-24

41. McNutt LA, Wu C, Xue $X$, Hafner JP. Estimating the relative risk in cohort studies and clinical trials of common outcomes. Am J Epidemiol. 2003; 157(10):940-3.

42. CDC. Asthma Facts - CDC's National Asthma Control Program Grantees. In: U.S. Department of Health and Human Services CfDCaP. Atlanta; 2013.

43. USDHHS. The health consequences of smoking: 50 years of progress. $A$ report of the surgeon general. In. Atlanta: U.S. Department of Health and Human Services, Centers for Disease Control and Prevention, National Center for Chronic Disease Prevention and Health Promotion, Office on Smoking and Health; 2014

44. Chronic Respiratory Disease (CDC). 2015. Gateway to Health Communication \& Social Marketing Practice. Retrieved 23 January, 2017 from https://www.cdc.gov/healthcommunication/toolstemplates/ entertainmented/tips/chronicrespiratorydisease.html.

45. NIH. What Causes COPD?. 2013. Retrieved 23 January, 2017, from https:// www.nhlbi.nih.gov/health/health-topics/topics/copd/causes.

46. Bhan N, Glymour MM, Kawachi I, Subramanian SV. Childhood adversity and asthma prevalence: evidence from 10 US states (2009-2011). BMJ Open Respir Res. 2014;1(1):e000016.

47. McEwen BS. Protective and damaging effects of stress mediators. N Engl J Med. 1998;338(3):171-9.

48. Wright RJ, Finn P, Contreras JP, Cohen S, Wright RO, Staudenmayer J, Wand M, Perkins D, Weiss ST, Gold DR. Chronic caregiver stress and lgE expression, allergen-induced proliferation, and cytokine profiles in a birth cohort predisposed to atopy. J Allergy Clin Immunol. 2004;113(6):1051-7.

49. Braveman P, Gottlieb L. The social determinants of health: it's time to consider the causes of the causes. Public Health Rep. 2014;129(Suppl 2):19-31.

50. Llabre MM, Schneiderman N, Gallo LC, Arguelles W, Daviglus ML, Gonzalez F 2nd, Isasi CR, Perreira KM, Penedo FJ. Childhood trauma and adult risk factors and disease in Hispanics/Latinos in the US: results from the Hispanic community health study/study of Latinos (HCHS/SOL) sociocultural ancillary study. Psychosom Med. 2017;79(2):172-80.

51. Remigio-Baker RA, Hayes DK, Reyes-Salvail F. Adverse childhood events are related to the prevalence of asthma and chronic obstructive pulmonary disorder among adult women in Hawaii. Lung. 2015:193(6):885-91.

52. Jordan HT, Stellman SD, Reibman J, Farfel MR, Brackbill RM, Friedman SM, Li J, Cone JE. Factors associated with poor control of 9/11-related asthma 10-11 years after the 2001 world trade center terrorist attacks. J Asthma. 2015;52(6):630-7.

53. Morello-Frosch R, Lopez R. The riskscape and the color line: examining the role of segregation in environmental health disparities. Environ Res. 2006;102(2):181-96.

54. Celedon JC, Roman J, Schraufnagel DE, Thomas A, Samet J. Respiratory health equality in the United States. The American thoracic society perspective. Ann Am Thorac Soc. 2014;11(4):473-9.

55. Steptoe A, Feldman PJ. Neighborhood problems as sources of chronic stress: development of a measure of neighborhood problems, and associations with socioeconomic status and health. Ann Behav Med. 2001;23(3):177-85.

56. Schulz AJ, Zenk SN, Israel BA, Mentz G, Stokes C, Galea S. Do neighborhood economic characteristics, racial composition, and residential stability predict perceptions of stress associated with the physical and social environment? Findings from a multilevel analysis in Detroit. J Urban Health. 2008;85(5): 642-61.
57. Yonas MA, Lange NE, Celedon JC. Psychosocial stress and asthma morbidity. Curr Opin Allergy Clin Immunol. 2012;12(2):202-10.

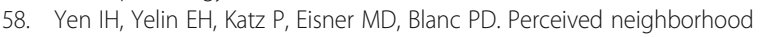
problems and quality of life, physical functioning, and depressive symptoms among adults with asthma. Am J Public Health. 2006;96(5):873-9.

59. Thoits PA. Stress and health: major findings and policy implications. J Health Soc Behav. 2010;51(Suppl):S41-53.

60. Mair C, Kaplan GA, Everson-Rose SA. Are there hopeless neighborhoods? An exploration of environmental associations between individual-level feelings of hopelessness and neighborhood characteristics. Health Place. 2012;18(2): 434-9.

61. Keller A, Litzelman K, Wisk LE, Maddox T, Cheng ER, Creswell PD, Witt WP. Does the perception that stress affects health matter? The association with health and mortality. Health Psychol. 2012;31(5):677-84.

62. Atkinson RW, Kang S, Anderson HR, Mills IC, Walton HA. Epidemiological time series studies of PM2.5 and daily mortality and hospital admissions: a systematic review and meta-analysis. Thorax. 2014;69(7):660-5.

63. Hsu HH, Chiu YH, Coull BA, Kloog I, Schwartz J, Lee A, Wright RO, Wright RJ. Prenatal particulate air pollution and asthma onset in urban children. Identifying sensitive windows and sex differences. Am J Respir Crit Care Med. 2015;192(9):1052-9.

64. Penman-Aguilar A, Talih M, Huang D, Moonesinghe R, Bouye K, Beckles G. Measurement of health disparities, health inequities, and social determinants of health to support the advancement of health equity. J Public health manag Pract. 2016;22(Suppl 1):S33-42.

65. Murgia N, Brisman J, Claesson A, Muzi G, Olin AC, Toren K. Validity of a questionnaire-based diagnosis of chronic obstructive pulmonary disease in a general population-based study. BMC Pulmon Med. 2014;14:49.

66. Bell J, Rubin V. Why place matters: building a movement for healthy communities in. Oakland: Policy Link - The California Endowment; 2007.

67. Morello-Frosch R, Zuk M, Jerrett M, Shamasunder B, Kyle AD. Understanding the cumulative impacts of inequalities in environmental health: implications for policy. Health Aff (Millwood). 2011;30(5):879-87.

\section{Ready to submit your research? Choose BMC and benefit from:}

- fast, convenient online submission

- thorough peer review by experienced researchers in your field

- rapid publication on acceptance

- support for research data, including large and complex data types

- gold Open Access which fosters wider collaboration and increased citations

- maximum visibility for your research: over $100 \mathrm{M}$ website views per year

At BMC, research is always in progress.

Learn more biomedcentral.com/submissions 